\title{
Exploring the Ambivalence of Time Pressure in Daily Working Life
}

\author{
Roman Prem, Matea Paškvan, Bettina Kubicek, and Christian Korunka \\ University of Vienna, Vienna, Austria
}

This article has been accepted for publication in International Journal of Stress Management: https://doi.org/10.1037/str0000044

(C) 2016 American Psychological Association. This article may not exactly replicate the authoritative document published in the APA journal. It is not the copy of record.

\section{Author Note}

Roman Prem, Matea Paškvan, Bettina Kubicek, and Christian Korunka, Department of Applied Psychology: Work, Education, Economy, Faculty of Psychology, University of Vienna, Vienna, Austria.

Matea Paškvan is now at the Department of Social Statistics, Statistics Austria, Vienna, Austria. Bettina Kubicek is now at Department of Informatics, Communications and Media, University of Applied Sciences Upper Austria, Hagenberg, Austria.

We thank Franziska Knoop and Petra Schinewitz for their help in collecting. This research was partly supported by the Austrian Science Fund (FWF): P23377G17.

Correspondence concerning this article should be addressed to Roman Prem, Department of Applied Psychology: Work, Education, Economy, Faculty of Psychology, University of Vienna, Universitätsstraße 7, A-1010 Vienna, Austria. E-mail: roman.prem@univie.ac.at 


\begin{abstract}
Today's workforce is often faced with high levels of time pressure. According to the challenge-hindrance stressor framework, high levels of time pressure should have an ambivalent relationship with task performance because time pressure increases both motivation and strain. To investigate these ambivalent relationships of time pressure in daily working life, we conducted a diary study over five workdays with measurements taken after work. Eighty-one participants provided data on a total of 294 workdays that were analyzed using Bayesian multilevel structural equation modeling techniques. Results revealed that time pressure had a significant total relationship with task performance on the person level, but not on the day level. Furthermore, our data showed that time pressure was positively related to indicators of strain-related and motivational processes, both at the person level and at the day level. However, multilevel mediation analyses also showed for both levels that time pressure was indirectly related to task performance only via motivational processes, but not via strainrelated processes. Our results suggest that between-person relationships of job stressors with work outcomes can differ from the corresponding within-person relationships. Thus, we recommend that future research investigates both motivational as well as strain-related processes for other job stressors not only on the person level but also on the day level. Finally, given the ambivalent nature of time pressure, we also recommend that practitioners keep relationships with both motivation and strain in mind when evaluating and redesigning work environments.
\end{abstract}

Keywords: time pressure, task performance, diary study, multilevel structural equation modeling, within-person processes 


\section{Exploring the Ambivalence of Time Pressure in Daily Working Life}

Time pressure has become an integral part of modern working life as today's workforce faces high levels of time pressure. For example, the majority of European workers reported working at very high speed and/or to tight deadlines at least a quarter of the time (Eurofound, 2012). These descriptions of working conditions almost perfectly resemble the definition of time pressure in the academic literature, described as the extent to which employees feel that they need to work at a pace faster than usual, or have insufficient time to finish their work tasks (Baer \& Oldham, 2006; Kinicki \& Vecchio, 1994).

According to the challenge-hindrance stressor framework (e.g., LePine, Podsakoff, \& LePine, 2005), time pressure should have ambivalent relationships with work outcomes because it triggers both motivational as well as strain-related processes. Although ambivalent relationships of time pressure with specific work outcomes have already been investigated on the person level (e.g., Widmer, Semmer, Kälin, Jacobshagen, \& Meier, 2012), previous research has failed to analyze the corresponding motivational and strain-related processes within persons. As a consequence, scholarly knowledge is limited in the way that it remains unknown if the ambivalent relationships of time pressure with work outcomes actually stem from processes that unfold within persons on the day level, or, if they exist only on the person level and thus have to be explained via different mechanisms depending on the level of analysis.

This paper aims to contribute to the literature by simultaneously considering motivational and strain-related processes in the relationships of time pressure with task performance on both the person level as well as the day level. The combination of a diary study design (e.g., Ohly, Sonnentag, Niessen, \& Zapf, 2010) with multilevel mediation analyses based on multilevel structure equation modeling (MSEM; Preacher, Zhang, \& 
Zyphur, 2011), enabled us to investigate indirect relationships of time pressure on task performance on the person level and the day level.

\section{The Challenge-Hindrance Stressor Framework}

Over the last years, researchers have started to take a new approach to job stressors, as some of them can be both 'good' and 'bad' with regard to certain outcomes. Although previous research had already shown that certain types of stressors may hold the potential for beneficial effects (i.e., eustress vs. distress; Selye, 1974), the introduction of the challengehindrance stressor framework (Cavanaugh, Boswell, Roehling, \& Boudreau, 2000) set off a more widespread adoption of differentiated approaches to stressors in research on job stress. In this stream of literature, researchers distinguish between two types of stressors: challenge stressors and hindrance stressors.

Both challenge stressors (e.g., time pressure, responsibility) and hindrance stressors (e.g., role ambiguity, red tape) put demands on employees' physical and mental resources. Consequently, job stressors of either type deplete employees' resources and thus contribute to strain and feelings of fatigue (Hockey, 1997; Meijman \& Mulder, 1998). However, in addition to such adverse effects that result from strain-related processes, challenge stressors (as opposed to hindrance stressors) also hold the potential for beneficial effects via motivational processes. Because employees often perceive challenge stressors as obstacles that, if overcome, add to goal achievement, challenge stressors elicit more active and problem-solving styles of coping (LePine et al., 2005; Van den Broeck, De Cuyper, De Witte, \& Vansteenkiste, 2010). Consequently, challenge stressors trigger not only strain-related but also motivational processes.

As a result of triggering both strain-related as well motivational processes, high levels of challenge stressors are not only associated with indicators of strain-related processes like exhaustion and burnout but also with indicators of motivational processes like vigor and 
engagement (Crawford, LePine, \& Rich, 2010; Van den Broeck et al., 2010). Further, because of their associations with indicators of both strain and motivation, challenge stressors also share ambivalent relationships with some work outcomes. Meta-analytic evidence shows for instance that challenge stressors and performance share positive indirect relationships via motivational processes as well as negative indirect relationships via strain-related processes (LePine et al., 2005). Because both indirect relationships neutralize each other to a large degree, researchers often only find small positive or sometimes non-significant relationships of challenge stressors with performance and other work outcomes (LePine et al., 2005; Widmer et al., 2012).

\section{The Ambivalence of Time Pressure in Daily Working Life}

Although ambivalent relationships with work outcomes are well-documented in the existing literature - not only for challenge stressors in general (e.g., LePine et al., 2005) but also for time pressure in particular (e.g., Widmer et al., 2012) - previous evidence is limited because it is largely based on cross-sectional data that only allow conclusions to be made on the person level. Albeit providing useful insights, studies focusing on person-level relationships neglect that the underlying motivational and strain-related processes should actually unfold within persons in daily working life. As a consequence, the ambivalent relationships of time pressure with work outcomes via both motivation and strain should not only be found on the person level but also on the day level. However, with a lack of empirical evidence, it remains unclear if the ambivalent relationship of time pressure and performance actually stems from within-person motivational and strain-related processes.

Previous research that investigated day-level effects of time pressure showed that time pressure has substantial fluctuations within persons on the day level (e.g., Ohly \& Fritz, 2010; Prem, Kubicek, Diestel, \& Korunka, 2016). Moreover, it has been documented that day-level time pressure triggers both motivational and strain-related processes within 
persons. For example, it has been shown that day-level time pressure is related to more daylevel proactive work behavior (Ohly \& Fritz, 2010). Consistent with assumptions derived from expectancy theory (e.g., Vroom, 1964) that time pressure fosters motivation because employees "are likely to believe that time pressure in the work context can be met with coping in the form of increased effort" (LePine et al., 2005, p. 766), Ohly and Fritz (2010) showed that the positive effects of day-level time pressure on day-level proactive work behavior can indeed be explained via day-level challenge appraisal. Similarly, regarding strain-related processes, research has shown that within-person processes link time pressure to employees' resource depletion (Prem et al., 2016). Drawing mainly on action regulation theory (Hacker \& Richter, 1990; see also Frese \& Zapf, 1994), Prem and colleagues (2016) showed that, as a stressor that disturbs the regulation of goal-directed work behavior, time pressure contributes to employee strain, not only through increases in experienced anxiety but also via increased effort required for volitional self-control. In sum, previous research has shown that time pressure is linked to both motivation and strain within persons on the day level.

In light of this previous empirical evidence and based on the assumption that the ambivalent person-level relationship of time pressure with task performance indeed arises from within-person processes, our study aimed to replicate previous person-level results on the day level. In order to simultaneously investigate how motivational and strain-related processes triggered by time pressure in daily working life affect employees' task performance, we conducted a diary study (Ohly et al., 2010). This procedure allowed us to explore both person-level as well as day-level relationships of time pressure in naturalistic work settings.

In our diary study, we decided to use proactive work behavior as a proxy for motivational processes and emotional exhaustion as a proxy for strain-related processes. In 
challenge-hindrance literature, it is assumed that challenge stressors "trigger positive emotions and an active or problem-solving style of coping (e.g., increasing effort)" (LePine et al., 2005, p. 765) and that motivation can be described as "the direction, level, and persistence of effort toward work" (p. 765). Because we believe that proactive work behavior (e.g., actively attacking problems, doing more than one is asked to) closely resembles the meaning of 'motivation' in the challenge-hindrance stressor framework, we decided to use proactive work behavior as a proxy for motivational processes in our study. Moreover, previous research had already established that time pressure triggers proactive work behavior on both the person level (Fay \& Sonnentag, 2002) as well as the day level (Ohly \& Fritz, 2010). Our decision to use emotional exhaustion (e.g., feeling burned out or used up from ones work) as a proxy for strainrelated processes was also based on challenge-hindrance literature (e.g., LePine et al., 2005; Crawford et al., 2010). Again, previous evidence suggested that high workload and time pressure are linked to emotional exhaustion on both the person level (Alarcon, 2011; Crawford et al., 2010) as well as on the day level (e.g., Ilies, Dimotakis, \& De Pater, 2010).

Assuming that the previously documented motivational and strain-related processes will be found not only on the person level, but also within persons on the day level, we proposed:

Hypothesis 1: Person-level time pressure and person-level task performance share (a) an overall positive total relationship, (b) a positive indirect relationship via person-level proactive work behavior as well as (c) a negative indirect relationship via person-level emotional exhaustion.

Hypothesis 2: Day-level time pressure and day-level task performance share (a) an overall positive total relationship, (b) a positive indirect relationship via day-level proactive work behavior as well as (c) a negative indirect relationship via day-level emotional exhaustion. 


\section{Method}

\section{Sample and Procedure}

To test our hypotheses, we invited knowledge workers from diverse occupations and industries (education, IT, marketing) to participate in a diary study (Ohly et al., 2010). We complied with APA ethical standards in the treatment of our sample. Participants were asked to complete a general survey assessing socio-demographic data as well as several diary surveys. The general survey had to be completed before beginning the diary surveys; diary surveys were completed on five consecutive workdays after participants finished their work.

The general survey was completed by 109 persons. We included participants in our analysis if they provided daily survey data on at least three working days. Overall, we were able to include 294 day-level data sets nested within 81 persons in our analyses. Of these 81 persons, $43(53.1 \%)$ were female. Mean age was 35.9 years $(S D=10.5)$; mean job tenure was 6.5 years $(S D=7.3)$. Average working time per week was 39.7 hours $(S D=8.3)$. About a quarter $(23.5 \%)$ of participants held a managerial position.

\section{Measures}

Age and gender were obtained from the general questionnaire; all other variables were measured using the diary surveys. We used abbreviated scales for all diary measures to reduce the participants' burden of filling out long scales, multiple times (Ohly et al., 2010). All diary measures were administered in German on 5-point scales $(1=$ not at all, $5=$ completely for time pressure; 1 = strongly disagree, 5 = strongly agree for all other scales). Table 1 displays the means, standard deviations, and zero-order correlations between the study variables, as well as Cronbach's alphas and percentage of variance at the day level.

Time pressure was assessed with three items adapted from the Instrument for Stressoriented Job Analysis (Semmer, Zapf, \& Dunckel, 1999; e.g., 'Today, I was pressed for time'). 
Proactive work behavior was assessed with three items adapted from the personal initiative scale by Frese, Fay, Hilburger, Leng, and Tag (1997; e.g. 'Today, I did more than I was asked to').

Emotional exhaustion was measured with three items adapted from the general scale of the Maslach Burnout Inventory (Schaufeli, Maslach, Leiter, \& Jackson, 1996; e.g., 'Right now, I feel burned out from my work').

Task performance was measured with three items adapted from the performance scale by Roe, Zinovieva, Dienes, and Ten Horn (2000; e.g., 'Today, I got good results from my work compared to the standards').

Negative affect was measured as a control variable with three items adapted from the Positive and Negative Affect Schedule (PANAS, Watson, Clark, \& Tellegan, 1988; e.g., 'Right now, I feel nervous').

To show that all the variables measured in the diary surveys represented empirically distinct constructs, we conducted multilevel confirmatory factor analyses (MCFAs) with Mplus 7.3 (Muthén \& Muthén, 1998-2012). The MCFAs confirmed a satisfactory fit of the hypothesized five-factor model $\left(\chi^{2}=245.6, d f=160\right.$, RMSEA $=.04$, CFI $=.95$, TLI $=.94$, $\mathrm{AIC}=11,001.1)$ that was superior to the best-fitting four-factor model $\left(\chi^{2}=312.8, d f=168\right.$, $\mathrm{RMSEA}=.05, \mathrm{CFI}=.92, \mathrm{TLI}=.90, \mathrm{AIC}=11,052.3)$, as well as the one-factor model $\left(\chi^{2}=\right.$ $1116.5, d f=180, \mathrm{RMSEA}=.13, \mathrm{CFI}=.50, \mathrm{TLI}=.42, \mathrm{AIC}=11,832.0)$.

\section{Data Analysis}

Since measurements at the day level were nested within persons, we conducted multilevel mediation analyses using MSEM (Preacher et al., 2011) in Mplus 7.3 (Muthén \& Muthén, 1998-2012). MSEM allowed us to conduct mediation analyses at multiple levels simultaneously, in a single analysis. By decomposing the variance of variables measured at the day level into their inter- and intra-individual components, MSEM accounts for the fact 
that relationships might differ on the person level and the day level. Consequently, multilevel mediation analyses with MSEM are less prone to biases than with other techniques.

In our model, time pressure was the predictor, proactive work behavior and emotional exhaustion were the mediators, and task performance was the outcome. We controlled for age and gender (grand-mean centered) at the person level, and for negative affect (person-mean centered) at the day level of our MSEM. Since the distribution of indirect relationships and indirect effects is skewed in most cases, we used Bayesian estimators calculated with Mplus 7.3 (Muthén \& Muthén, 1998-2012) default (non-informative) priors and means for point estimates in our analyses, to obtain unbiased Bayesian credibility intervals [CIs] for the indirect relationships.

\section{Results}

\section{Preliminary Analyses}

Before testing our hypotheses, we examined the degree of person-level and day-level variance of our variables. As shown in Column 7 of Table 1, there were substantial proportions of day-level variance, ranging between $40 \%$ (for emotional exhaustion) and 63\% (for time pressure and proactive work behavior), thus calling for a multilevel approach to data analysis.

[Insert Table 1 about here]

\section{Hypothesis Testing}

We tested both our hypotheses at once in a single MSEM model. Figure 1 illustrates both person-level and day-level estimates from the MSEM.

[Insert Figure 1 about here]

On the person level, our analysis revealed a significant positive total relationship of time pressure with task performance (Hypothesis 1a). Further, time pressure was positively related to both mediators - proactive work behavior and emotional exhaustion - on the 
person level. Person-level proactive work behavior was positively associated with personlevel task performance, but there was no significant relationship between person-level emotional exhaustion and person-level task performance. Consequently, our data revealed that the person-level association of time pressure and task performance could be explained via proactive work behavior (Hypothesis $1 \mathrm{~b}$ ), $\gamma=0.200,95 \%$ Bayesian CI [0.036, 0.477], but not via emotional exhaustion (Hypothesis 1c), $\gamma=-0.014,95 \%$ Bayesian CI [-0.107, 0.069]. Thus, Hypotheses 1a and 1b were supported, while Hypothesis 1c had to be rejected.

On the day level, we found no significant total relationship between time pressure and task performance (Hypothesis 2a). Day-level time pressure was positively related to both mediators - proactive work behavior and emotional exhaustion. Again, day-level proactive work behavior was positively associated with day-level task performance, but there was no significant relationship between day-level emotional exhaustion and day-level task performance. Consequently, we found only a significant indirect relationship between daylevel time pressure and day-level task performance via day-level proactive work behavior (Hypothesis 2b), $\gamma=0.028,95 \%$ Bayesian CI [0.003, 0.057], but not via day-level emotional exhaustion (Hypothesis 2c), $\gamma=-0.004,95 \%$ Bayesian CI [-0.021, 0.010]. Therefore, Hypothesis $2 \mathrm{~b}$ was supported, whereas Hypotheses $2 \mathrm{a}$ and $2 \mathrm{c}$ had to be rejected.

\section{Discussion}

Our diary study revealed that employees who experience more time pressure in general also report better general task performance. However, our results also indicate that on days with higher time pressure, employees' task performance was not significantly higher than on days with lower time pressure. Our analysis further revealed that on both the person as well as the day level, time pressure was indirectly related to task performance through proactive work behavior, indicating that time pressure triggers motivational processes at both levels. However, the assumption that time pressure has adverse indirect relationships with 
task performance via strain-related processes (measured via higher emotional exhaustion) was not supported on either level. Nevertheless, the pattern of the direct relationships of time pressure with proactive work behavior and emotional exhaustion matched our assumptions on both levels. This indicates that, although only motivational processes seem to link time pressure to task performance, time pressure is indeed linked to motivation as well as strain on both the person and the day level.

Although previous meta-analyses already documented that the relationship of motivation and performance is stronger than the relationship of strain and performance (LePine et al., 2005), it was still unexpected that we did not find any relationships between emotional exhaustion and task performance on either level of analysis. A potential explanation for not finding the otherwise well-established effects of emotional exhaustion on task performance (e.g., Taris, 2006) could be that, although time pressure may lead to increased compensatory effort that promotes strain (e.g., Hockey, 1997; Prem et al., 2016), task performance might only be negatively affected by emotional exhaustion, if employees are insufficiently able to replenish their invested resources over longer periods of time (cf. Meijman \& Mulder, 1998). Thus, one might argue that the processes that link strain to impaired task performance require longer periods of time than can be captured with typical diary study designs. Alternatively, the missing relationships between emotional exhaustion and task performance could also be explained by considering that specific personal or job resources helped the knowledge workers in our sample to effectively cope with time pressure. For example, high levels of job resources like job control or job autonomy could have boosted motivational processes and/or buffered strain-related processes (cf. Kühnel, Sonnentag, \& Bledow, 2012; Prem et al., 2016).

As a consequence of not finding the hypothesized strain-related processes as a mediator between time pressure and task performance, we recommend that future research obtains repeated measurements within persons over much longer periods of time than are 
usually covered in typical diary studies. Day-level studies that extend over longer periods of time would also allow researchers to investigate how transient (day-level) and chronic (person-level) effects are linked over time, and thus help to further advance scholarly knowledge by integrating both perspectives (cf. Ilies, Aw, \& Lim, 2016; Ilies, Aw, \& Pluut, 2015). Additionally, we would recommend for future research based on the challengehindrance stressor framework (e.g., LePine et al., 2005) to examine the within-person motivational and strain-related processes for other job stressors as well, and to consider potential moderators (e.g., job autonomy, social support) in these processes.

\section{Strengths and Limitations}

As with all research, our study comes with both strengths and limitations. A major strength of our study is that the usage of a diary design allowed us to investigate relationships between time pressure and task performance in naturalistic work settings. Consequently, our study sheds light on the within-person processes triggered by time pressure in daily working life. Furthermore, using Bayesian MSEM techniques we were able to conduct multilevel mediation analyses regarding the motivational and strain-related processes triggered by time pressure, simultaneously on the person level and the day level. This allowed us to draw implications for future studies based on the challenge-hindrance stressor framework (e.g., LePine et al., 2005).

One limitation of our study that should be mentioned is that it was based on selfreport data. This may raise questions of common-method bias. However, our MCFAs showed that all concurrently measured constructs represented empirically distinct constructs, and we controlled for negative affect as a potential source of common-method bias in our analysis. To rule out further sources of common-method bias, future research could separate the measures across time and/or obtain data from different sources (e.g., supervisor ratings). 
Another limitation of our diary study lies in the selection of our proxy measures for the investigated motivational and strain-related processes. We decided to measure proactive work behavior and emotional exhaustion based on previous research within the challengehindrance stressor framework (e.g., Crawford et al., 2010; LePine et al., 2005; Ohly \& Fritz, 2010). However, one could argue that motivational and strain-related processes could have also been operationalized with other measures. Future research might want to include additional measures that tap motivational and strain-related processes. For example, future studies could include ratings on work engagement and organization-based self-esteem as additional proxies for motivational processes (e.g. Crawford et al., 2010; Widmer et al., 2012), as well as ego depletion and irritation as additional proxies for strain-related processes (e.g., Prem et al., 2016; Widmer et al., 2012).

Finally, it should be noted that our decision to use a sample of knowledge workers also potentially limits the generalizability of our findings. Because it has been shown that nurses, for example, tend to appraise time pressure as a hindrance rather than as a challenge (Bakker \& Sanz-Vergel, 2013), one might assume differences in the underlying withinperson processes between knowledge work and human service work. Thus, we recommend that future research tests the generalizability of our findings, either in service work in general, or more specifically in particular professions, like nursing.

\section{Practical Implications and Conclusion}

Our diary study has shown that although high levels of time pressure on a given day trigger motivational processes on that specific day, high levels of time pressure on a given day are not associated with task performance on that specific day. However, time pressure is associated with increased levels of emotional exhaustion on the day level. Consequently, we recommend that practitioners remain aware of ambivalent relationships of time pressure with motivation as well as strain when evaluating and redesigning work environments. 
In conclusion, we want to encourage other researchers to investigate within-person processes on the day level in their studies on occupational stress and/or organizational behavior. To advance academic knowledge, future diary studies should continue to explore the mechanisms underlying stressor-strain relationships in daily working life. 


\section{References}

Alarcon, G. M. (2011). A meta-analysis of burnout with job demands, resources, and attitudes. Journal of Vocational Behavior, 79, 549-562. http://dx.doi.org/10.1016/j.jvb.2011.03.007

Baer, M., \& Oldham, G. R. (2006). The curvilinear relation between experienced creative time pressure and creativity: Moderating effects of openness to experience and support for creativity. Journal of Applied Psychology, 91, 963-970. http://dx.doi.org/10.1037/0021-9010.91.4.963

Bakker, A. B., \& Sanz-Vergel, A. I. (2013). Weekly work engagement and flourishing: The role of hindrance and challenge job demands. Journal of Vocational Behavior, 83, 397-409. http://dx.doi.org/10.1016/j.jvb.2013.06.008

Cavanaugh, M. A., Boswell, W. R., Roehling, M. V., \& Boudreau, J. W. (2000). An empirical examination of self-reported work stress among US managers. Journal of Applied Psychology, 85, 65-74. http://dx.doi.org/10.1037//0021-9010.85.1.65

Crawford, E. R., LePine, J. A., \& Rich, B. L. (2010). Linking job demands and resources to employee engagement and burnout: A theoretical extension and meta-analytic test. Journal of Applied Psychology, 95, 834-848. http://dx.doi.org/10.1037/a0019364

Eurofound. (2012). Fifth European Working Conditions Survey. Luxembourg, Luxembourg: Publications Office of the European Union.

Fay, D., \& Sonnentag, S. (2002). Rethinking the effects of stressors: A longitudinal study on personal initiative. Journal of Occupational Health Psychology, 7, 221-234. http://dx.doi.org/10.1037/1076-8998.7.3.221

Frese, M., Fay, D., Hilburger, T., Leng, K., \& Tag, A. (1997). The concept of personal initiative: Operationalization, reliability and validity in two German samples. Journal 
of Occupational and Organizational Psychology, 70, 139-161.

http://dx.doi.org/10.1111/j.2044-8325.1997.tb00639.x

Frese, M., \& Zapf, D. (1994). Action as the core of work psychology: A German approach. In H. C. Triandis, M. D. Dunnette, \& L. M. Hough (Eds.), Handbook of Industrial and Organizational Psychology (Vol. 4, pp. 271-340). Palo Alto, CA: Consulting Psychologists Press.

Hacker, W., \& Richter, P. (1990). Psychische Regulation von Arbeitstätigkeiten - Ein Konzept in Entwicklung [Mental regulation of work activities - A developing concept]. In F. Frei \& I. Udris (Eds.), Das Bild der Arbeit [The image of work] (pp. 125-142). Bern, Switzerland: Huber.

Hockey, G. R. J. (1997). Compensatory control in the regulation of human performance under stress and high workload: A cognitive-energetical framework. Biological Psychology, 45, 73-93. http://dx.doi.org/10.1016/S0301-0511(96)05223-4

Ilies, R., Aw, S. S., \& Lim, V. K. (2016). A naturalistic multilevel framework for studying transient and chronic effects of psychosocial work stressors on employee health and well-being. Applied Psychology, 65, 223-258. http://dx.doi.org/10.1111/apps.12069

Ilies, R., Aw, S. S., \& Pluut, H. (2015). Intraindividual models of employee well-being: What have we learned and where do we go from here? European Journal of Work and Organizational Psychology, 24, 827-838.

http://dx.doi.org/10.1080/1359432X.2015.1071422

Ilies, R., Dimotakis, N., \& De Pater, I. E. (2010). Psychological and physiological reactions to high workloads: Implications for well-being. Personnel Psychology, 63, 407-436. http://dx.doi.org/10.1111/j.1744-6570.2010.01175.x 
Kinicki, A. J., \& Vecchio, R. P. (1994). Influences on the quality of supervisor-subordinate relations: The role of time-pressure, organizational commitment, and locus of control. Journal of Organizational Behavior, 15, 75-82. http://dx.doi.org/10.1002/job.4030150108

Kühnel, J., Sonnentag, S., \& Bledow, R. (2012). Resources and time pressure as day-level antecedents of work engagement. Journal of Occupational and Organizational Psychology, 85, 181-198. http://dx.doi.org/10.1111/j.2044-8325.2011.02022.x

LePine, J. A., Podsakoff, N. P., \& LePine, M. A. (2005). A meta-analytic test of the challenge stressor-hindrance stressor framework: An explanation for inconsistent relationships among stressors and performance. Academy of Management Journal, 48, 764-775. http://dx.doi.org/10.5465/AMJ.2005.18803921

Meijman, T.F., \& Mulder, G. (1998). Psychological aspects of workload. In P.J. Drenth, H. Thierry, \& C.J. de Wolff. (Eds.), Handbook of Work and Organizational Psychology, Vol. 2: Work psychology (pp. 5-33). Hove, UK: Psychology Press.

Muthén, L. K., \& Muthén, B. O. (1998-2012). Mplus User's Guide (7th ed.). Los Angeles, CA: Muthén \& Muthén.

Ohly, S., \& Fritz, C. (2010). Work characteristics, challenge appraisal, creativity, and proactive behavior: A multi-level study. Journal of Organizational Behavior, 31, 543565. http://dx.doi.org/10.1002/job.633

Ohly, S., Sonnentag, S., Niessen, C. \& Zapf, D. (2010). Diary studies in organizational research: An introduction and some practical recommendations. Journal of Personnel Psychology, 9, 79-93. http://dx.doi.org/10.1027/1866-5888/a000009

Preacher, K. J., Zhang, Z., \& Zyphur, M. J. (2011). Alternative methods for assessing mediation in multilevel data: The advantages of multilevel SEM. Structural Equation Modeling, 18, 161-182. http://dx.doi.org/10.1080/10705511.2011.557329 
Prem, R., Kubicek, B., Diestel, S., \& Korunka, C. (2016). Regulatory job stressors and their within-person relationships with ego depletion: The roles of state anxiety, self-control effort, and job autonomy. Journal of Vocational Behavior, 92, 22-32. http://dx.doi.org/10.1016/j.jvb.2015.11.004

Roe, R., Zinovieva, I., Dienes, E., \& Ten Horn, L. (2000). A comparison of work motivation in Bulgaria, Hungary, and the Netherlands: Test of a model. Applied Psychology, 49, 658-687. http://dx.doi.org/10.1111/1464-0597.00039

Schaufeli, W. B., Leiter, M. P., Maslach, C. \& Jackson, S. E. (1996). Maslach Burnout Inventory - General Survey (MBI-GS). In C. Maslach, S. E. Jackson \& M. P. Leiter. Maslach Burnout Inventory Manual (3rd ed.). Palo Alto, CA: Consulting Psychologists Press.

Selye, H. (1974). Stress without distress. Philadelphia, PA: Lippincott.

Semmer, N. K., Zapf, D., \& Dunckel, H. (1999). Instrument zur stressbezogenen Tätigkeitsanalyse ISTA [Istrument for stress-related task analysis]. In H. Dunckel (Ed.), Handbuch psychologischer Arbeitsanalyseverfahren [Handbook of psychological tools for work analysis] (pp. 179-204). Zürich, Switzerland: vdf.

Taris, T. W. (2006). Is there a relationship between burnout and objective performance? A critical review of 16 studies. Work \& Stress, 20, 316-334. http://dx.doi.org/10.1080/02678370601065893

Van den Broeck, A., De Cuyper, N., De Witte, H., \& Vansteenkiste, M. (2010). Not all job demands are equal: Differentiating job hindrances and job challenges in the Job Demands-Resources model. European Journal of Work and Organizational Psychology, 19, 735-759. http://dx.doi.org/10.1080/13594320903223839

Vroom, V. H. (1964). Work and motivation. New York, NY: Wiley. 
Watson, D., Clark, L. A., \& Tellegen, A. (1988). Development and validation of brief measures of positive and negative affect: The PANAS scales. Journal of Personality and Social Psychology, 54, 1063-1070. http://dx.doi.org/10.1037/00223514.54.6.1063

Widmer, P. S., Semmer, N. K., Kälin, W., Jacobshagen, N., \& Meier, L. L. (2012). The ambivalence of challenge stressors: Time pressure associated with both negative and positive well-being. Journal of Vocational Behavior, 80, 422-433.

http://dx.doi.org/10.1016/j.jvb.2011.09.006 
Table 1. Means, standard deviations, Cronbach's alphas, day-level variance, and zero-order correlations of study variables

\begin{tabular}{|c|c|c|c|c|c|c|c|c|c|c|c|c|c|}
\hline & $M^{a}$ & $S D^{a}$ & $S D^{b}$ & $\alpha^{\mathrm{c}}$ & $\alpha^{\mathrm{d}}$ & $1-\mathrm{ICC}^{\mathrm{e}}$ & 1 & 2 & 3 & 4 & 5 & 6 & 7 \\
\hline 1 Time pressure & 2.42 & 0.67 & 0.87 & .93 & .82 & $63 \%$ & - & .16 & .30 & .11 & .38 & & \\
\hline 2 Proactive work behavior & 3.21 & 0.55 & 0.72 & .69 & .65 & $63 \%$ & .62 & - & -.03 & .38 & .04 & & \\
\hline 3 Emotional exhaustion & 2.25 & 0.83 & 0.68 & .97 & .86 & $40 \%$ & .46 & .05 & - & -.05 & .31 & & \\
\hline 4 Task performance & 3.10 & 0.33 & 0.41 & .68 & .72 & $60 \%$ & .42 & .64 & -.02 & - & -.05 & & \\
\hline 5 Negative affect & 1.72 & 0.59 & 0.64 & .86 & .67 & $54 \%$ & .51 & .09 & .70 & .14 & - & & \\
\hline 6 Age & 35.87 & 10.46 & - & - & - & - & .34 & .26 & .32 & .09 & .06 & - & \\
\hline 7 Gender $^{\mathrm{f}}$ & 1.47 & 0.50 & - & - & - & - & .28 & .06 & .15 & .06 & .10 & .27 & - \\
\hline
\end{tabular}

Note. Correlations below the diagonal are person-level correlations $(\mathrm{N}=81)$.

Correlations above the diagonal are day-level correlations $(n=294)$.

Numbers in bold indicate $p<.05$ for correlations.

${ }^{a}$ Means and standard deviations at the person level.

${ }^{\mathrm{b}}$ Standard deviations at the day level.

${ }^{c}$ Multilevel Cronbach's alphas at person level.

${ }^{\mathrm{d}}$ Multilevel Cronbach's alphas at day level.

e 1 -ICC $=$ Percentage of variance at the day level; ICC = variance at person level / (variance at day level + variance at person level).

${ }^{\mathrm{f}} \operatorname{Gender}(1=$ female, 2 = male $)$. 


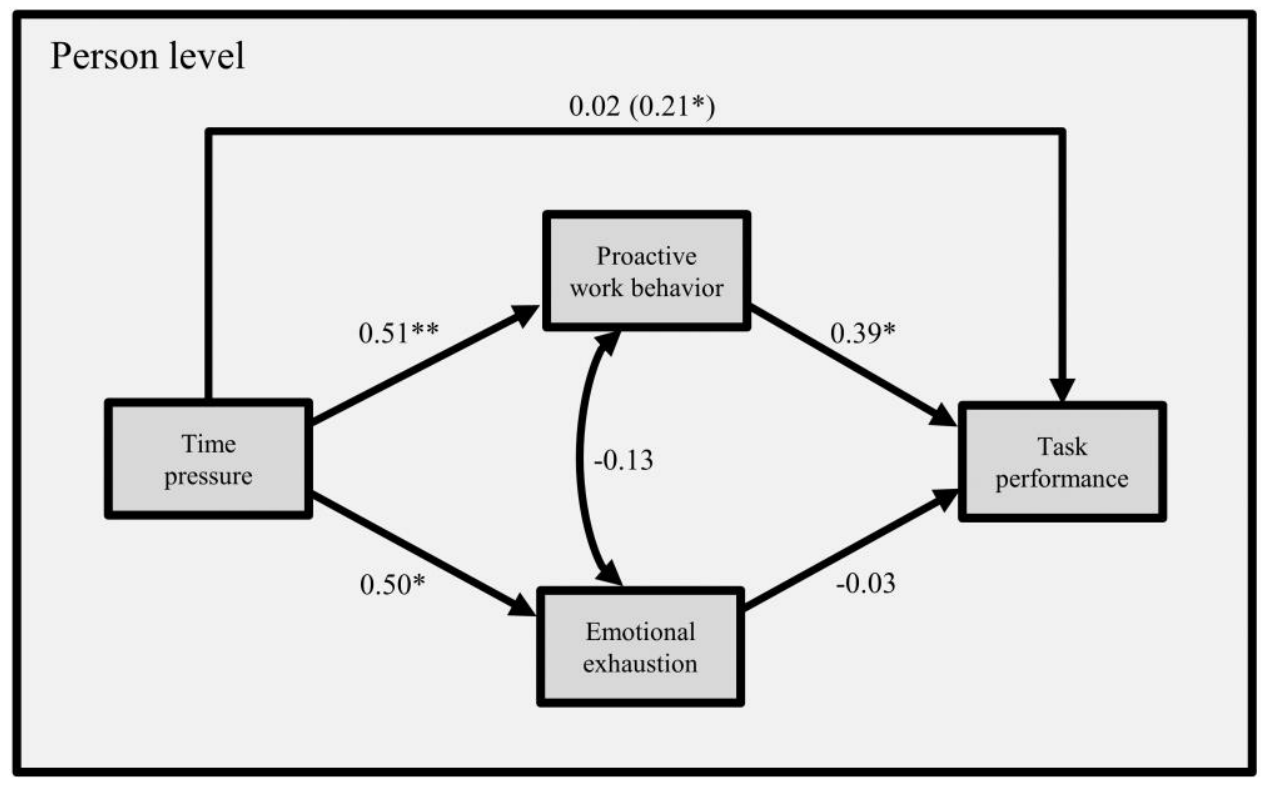

\section{Day level}

\section{$0.04(0.07)$}

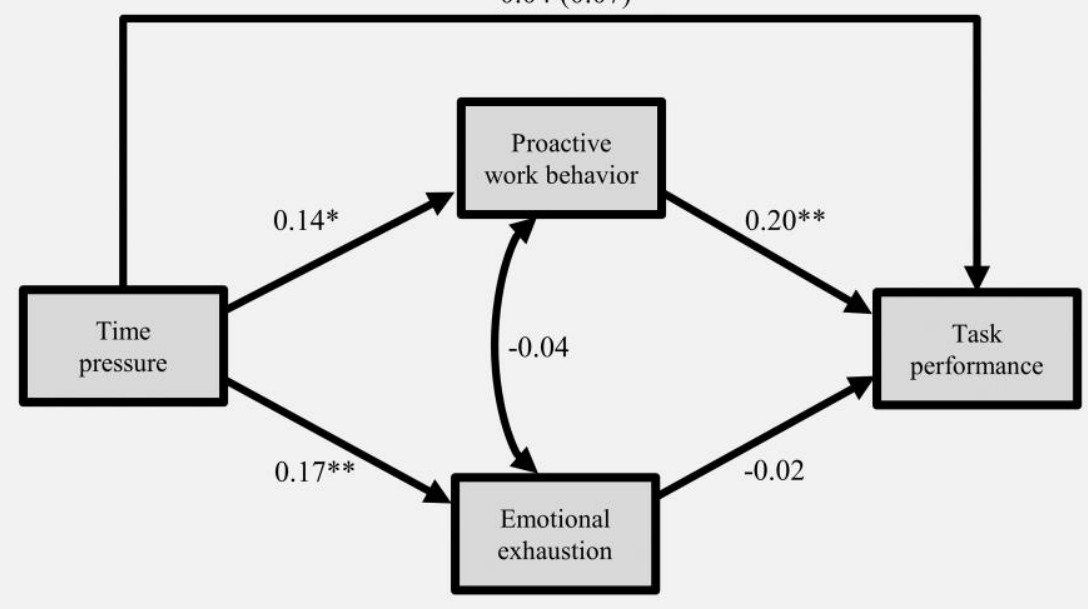

Figure 1. Estimates from Bayesian multilevel structural equation modeling.

Note. This figure shows unstandardized estimates. Person-level estimates are controlled for age and gender; day-level estimates are controlled for negative affect. The estimates in parentheses indicate the total relationships between time pressure and task performance. $* p<.05 ; * * p<.01$ 